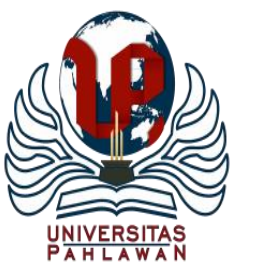

Jurnal Basicedu Volume 4 Nomor 4 Tahun 2020 Halm. 850 - 860

JURNAL BASICEDU

Research \& Learning in Elementary Education

https://jbasic.org/index.php/basicedu/index

\title{
Pengaruh Model Pembelajaran TGT (Teams Games Tournament) Ditinjau dari Kemampuan Berpikir Kritis pada Pembelajaran Tematik di Sekolah Dasar
}

\author{
Nur Endah Hikmah Fauziyah ${ }^{1}$, Indri Anugraheni ${ }^{2}$ \\ Universitas Kristen Satya Wacana, Jawa Tengah, Indonesia ${ }^{1,2}$ \\ E-mail: 292016154@student.uksw.edu', indri.anugraheni@uksw.edu ${ }^{2}$
}

\begin{abstract}
Abstrak
Penelitian ini bertujuan untuk mengetahui pengaruh kemampuan berpikir kritis pada pembelajaran tematik siswa kelas V SDN Blotongan 03 Tahun Ajaran 2019/2020 sebelum dan setelah menggunakan model pembelajaran TGT (Teams Games Tournament). Populasi dan sampel penelitian yang digunakan adalah siswa kelas V SDN Blotongan 03 yang berjumlah 31 siswa. Metode penelitian yang digunakan adalah metode Pre-eksperimental dengan tipe Onegroup Pre-test-Post-test Design. Dalam pengumpulan data, instrumen yang digunakan yaitu tes berupa uraian dan dokumentasi. Analisis data berupa data kuantitatif yaitu perhitungan rata-rata nilai pre-test-post-test, uji normalitas, uji homogenitas, dan uji one sample T-test menggunakan teknik one samples test dengan bantuan SPSS 20. Hasil penelitian: 1) kemampuan berpikir kritis pada pembelajaran tematik siswa sebelum menggunakan model pembelajaran TGT (Teams Games Tournament) nilai rata-rata sebesar 63,27. 2) kemampuan berpikir kritis pada pembelajaran tematik siswa setelah menggunakan model pembelajaran TGT (Teams Games Tournament) nilai ratarata sebesar 74,12. 3) hasil analisis data one sample T-test menggunakan teknik one samples test diperoleh hasil $\mathrm{t}$ hitung 60,208 > t tabel 1,698 dan nilai signifikansi <0,05 $(0,000<0,05)$. Maka dapat disimpulkan bahwa terdapat pengaruh kemampuan berpikir kritis pada pembelajaran tematik siswa kelas V SDN Blotongan 03 Tahun Ajaran 2019/2020 dengan menggunakan model pembelajaran TGT (Teams Games Tournament).
\end{abstract}

Kata kunci: model pembelajaran TGT (Teams Games Tournament); kemampuan berpikir kritis.

\begin{abstract}
This study aims to determine the effect of critical thinking skills on the thematic learning of fifth grade students of Blotongan Elementary School 03 Academic Year 2019/2020 before and after using the TGT (Teams Games Tournament) learning model. The population and research sample used were grade $V$ students of Blotongan Elementary School 03, totaling 31 students. The research method used is the Pre-experimental method with the type of One-group Pre-test-Post-test Design. In collecting data, the instrument used is a test in the form of a description and documentation. Data analysis in the form of quantitative data is the calculation of the average pretest-post-test, normality test, homogeneity test, and one sample T-test using one samples test with the help of SPSS 20. The results of the study: 1) critical thinking skills the students' thematic learning before using the TGT (Teams Games Tournament) learning model averaged 63.27. 2) critical thinking skills in students' thematic learning after using the TGT (Teams Games Tournament) learning model an average value of 74.12. 3) the results of the analysis of one sample T-test data using the one samples test obtained the results of $t$ count 60.208>t table 1.698 and the significance value $<0.05(0.000<0.05)$. Then it can be concluded that there is an influence of critical thinking ability on the thematic learning of fifth grade students of Blotongan ELemtary School 03 Academic Year 2019/2020 using the TGT (Teams Games Tournament) learning model.
\end{abstract}

Keywords: the learning model TGT (Teams Games Tournament); critical thinking ability.

Copyright (c) 2020 Nur Endah Hikmah Fauziyah, Indri Anugraheni

$\triangle$ Corresponding author :

Address : Universitas Kristen Satya Wacana $\quad$ ISSN 2580-3735 (Media Cetak)

Email : 292016154@student.uksw.edu ISSN 2580-1147 (Media Online)

Phone :

DOI: $10.31004 /$ basicedu.v4i4.459 
Kritis pada Pembelajaran Tematik di Sekolah Dasar - Nur Endah Hikmah Fauziyah, Indri Anugraheni.

DOI: $10.31004 /$ basicedu.v4i4.459

\section{PENDAHULUAN}

Peranan pendidikan sangat penting bagi setiap bangsa, karena kelangsungan hidup dan kemajuan suatu bangsa, khususnya bagi Negara yang sedang berkembang ditentukan oleh kemajuan sebuah pendidikan. Lembaga pendidikan merupakan upaya paling utama dalam meningkatkan kualitas sumber daya manusia. Sebagaimana telah tercantum dalam UndangUndang Republik Indonesia No. 20 Tahun 2003 tentang Sistem Pendidikan Nasional bahwa pendidik nasional pada hakikatnya berfungsi untuk mengembangkan kemampuan dan membentuk watak serta peradaban bangsa yang bermartabat dalam rangka mencerdaskan kehidupan bangsa, selain itu pendidikan juga bertujuan untuk mengembangkan potensi siswa agar menjadi manusia yang beriman dan bertakwa kepada Tuhan Yang Maha Esa, berakhlak mulia, sehat, berilmu, cakap, kreatif, mandiri, dan menjadi warga Negara yang demokratis.

Berdasarkan isi Undang-Undang Republik Indonesia No. 20 Tahun 2003 tentang Sistem Pendidikan Nasional menunjukkan bahwa tenaga pendidikan, khususnya para guru diharapkan mampu meningkatkan kualitas pendidikan di Indonesia. Seperti yang dinyatakan (Anugraheni, 2017:247) tugas seorang pendidikan yaitu meningkatkan kualitas, kreativitas, dan mengembangkan potensi yang dimiliki peserta didik. Salah satu cara untuk meningkatkan kualitas pendidikan yaitu guru mampu mendidik siswa agar terlibat aktif serta menstimulus atau merangsang pikiran siswa secara mendalam untuk memecahkan suatu masalah terkait materi pembelajaran. Hal ini mendukung pendapat (Ni Md. Rusnadi, 2013:2) yaitu guru harus mengubah kegiatan pembelajaran yang aktif dan kreatif dengan cara lebih menekankan pada kemampuan siswa dan kegiatan pembelajaran tidak berpusat pada guru. Sejalan dengan pendapat (Surata et al., 2013:2) bahwa belajar akan lebih bermakna jika siswa mengalami perubahan yaitu memahami apa yang dipelajari, bukan hanya sekedar menghafal konsep materi pelajaran.

Memasuki pendidikan di era abad 21 saat ini, (Huda, 2013:87) berpendapat bahwa dengan adanya persaingan pendidikan pada abad 21 saat ini menuntut paradigma pendidikan untuk merubah metodologi pembelajaran yang awalnya berpusat pada bimbingan guru (teacher-centered) beralih menjadi berpusat pada pengembangan kemampuan siswa (student-centered). Sesuai perubahan metodologi pembelajaran abad 21 menunjukkan bahwa peran guru sangat penting untuk mendidik siswa agar terlibat aktif dalam memahami konsep, menganalisis suatu masalah serta memecahkan suatu masalah, dan mentransfer apa yang mereka pelajari untuk menjadikan pengalaman atau suatu pelajaran yang bermakna agar siswa dapat menerapkan ilmunya dalam kehidupan sehari-hari. Sejalan dengan berlakunya kurikulum 2013 saat ini yang menerapkan pembelajaran tematik. Menurut Permendikbud No. 22 Tahun 2016 pada hakikatnya pembelajaran pada Kurikulum 2013 dilaksanakan secara tematik terpadu. Pembelajaran tematik merupakan pembelajaran terpadu yang menggunakan tema untuk mengkaitkan beberapa mata pelajaran sehingga dapat memberikan pengalaman belajar yang bermakna kepada siswa. 
Melalui implementasi pembelajaran tematik guru dapat mendidik siswa agar terlibat aktif dan menumbuhkan kemampuan berpikir kritis siswa untuk mengkaji setiap permasalahan yang ada.

Hal ini mendukung pendapat (Anugraheni, 2019:277) berpikir kritis adalah kemampuan yang dimiliki siswa dalam proses berpikir dengan cara menganalisis, menghubungkan, menganalisis serta mengkreasikan berbagai aspek dalam situasi atau terhadap permasalahan yang diberikan. Sedangkan menurut (Winoto, 2020:231) berpikir kritis merupakan terjadinya proses berpikir untuk mengolah pengetahuan yang diperoleh secara terorganisir dengan cara mengkritisi, memilih, memecahkan suatu masalah, membuat sebuah keputusan, mengevaluasi adanya fakta atau asumsi serta logika dengan alasan yang rasional dan dapat dipertanggungjawabkan. Sejalan dengan pendapat Gerhand dalam (Maulana, 2017:6) menyatakan bahwa berpikir kritis adalah sebagai proses yang kompleks karena melibatkan penerimaan serta penguasaan data, menganalisis data, melakukan evalusi, serta membuat seleksi atau membuat sebuah keputusan berdasarkan hasil evaluasi. Berdasarkan pendapat diatas dapat disimpulkan bahwa berpikir kritis merupakan terjadinya proses berpikir untuk menganalisis, memecahkan suatu masalah, mengevaluasi, menyeleksi, mengevaluasi dan membuat keputusan berdasarkan masalah yang telah dikaji.

(Winoto, 2020:229) menyatakan bahwa rendahnya tingkat kemampuan berpikir kritis siswa disebabkan oleh penerapan model pembelajaran yang kurang inovatif dan tidak berpusat pada siswa. Sehingga diperlukan model pembelajaran yang inovatif untuk dapat menjadikan siswa aktif dan menumbuhkan kemampuan berpikir kritis. Salah satu model pembelajaran yang dapat menjadikan siswa aktif dan menumbuhkan kemampuan berpikir kritis yaitu dengan menggunakan model pembelajaran kooperatif tipe TGT (Teams Games Tournament). (Slavin, 2010:13) menyatakan bahwa model pembelajaran kooperatif tipe TGT memiliki tujuan yaitu untuk memotivasi siswa supaya saling mendukung dan membantu satu sama lain dalam menguasai kemampuan yang diajarkan oleh guru yang pada akhirnya untuk memperoleh skor pada masingmasing anggota tim. Sehingga siswa berusaha menguasai materi dengan baik, maka dengan cara tersebut akan berdampak terhadap berpikir kritis siswa. Model pembelajaran kooperatif tipe TGT menurut (Slavin, 2010:8) yaitu merupakan suatu model pembelajaran dengan cara melakukan pertandingan permainan antar tim atau antar anggota kelompok. Pada mulanya dikembangkan oleh David DeVries dan Keith Edwards pada tahun 1995. Sedangkan model pembelajaran TGT menurut (Hermawan, 2020:468) yaitu dengan cara membentuk kelompok kecil yang terdiri dari empat sampai enam orang yang memiliki latar belakang kemampuan dalam akademik, gender atau jenis kelamin, ras, atau suku yang berbeda. Adapun langkah-langkah dalam menerapkan model pembelajaran TGT menurut (Pardede, 2019:68) yaitu 1) penyajian kelas, 2) membentuk kelompok secara heterogen, 3) melaksanakan permainan, 4) melaksanakan pertandingan atau turnamen, 5) memberikan sebuah penghargaan. Berdasarkan pendapat diatas dapat disimpulkan 
Kritis pada Pembelajaran Tematik di Sekolah Dasar - Nur Endah Hikmah Fauziyah, Indri Anugraheni.

DOI: 10.31004/basicedu.v4i4.459

bahwa model pembelajaran TGT merupakan model pembelajaran dengan cara membuat tim belajar yang terdiri dari empat sampai enam orang, dibentuk secara heterogen untuk saling menguasai materi dengan baik, kemudian dilakukan permainan turnamen atau pertandingan antar tim untuk memperoleh poin tambahan yang nantinya dijadikan skor tim mereka. Tahap terakhir yaitu memberikan sebuah penghargaan bagi tim yang memperoleh skor tertinggi.

(Lailatifah, 2018:6-7) telah melakukan penelitian tentang Efektivitas Model Pembelajaran TGT dan STAD Ditinjau Dari Kemampuan Berpikir Kritis. Hasil penelitian menunjukkan bahwa model pembelajaran TGT lebih efektif dibandingkan model pembelajaran STAD. Hal ini dapat dilihat dari skor yang diperoleh model pembelajaran TGT rata-rata yaitu 28,7. Sedangkan model pembelajaran STAD mendapat skor ratarata yaitu 15,5 . Perbedaan rata-rata membuktikan bahwa model pembelajaran TGT lebih efektif dibandingkan model pembelajaran STAD. Penelitian lain dilakukan oleh (Susilo, 2019:133) mengenai Penerapan Permainan What's In Here Berbasis Model TGT untuk Menumbuhkan Kemampuan Berpikir Kritis Siswa. Hasil penelitian menunjukkan bahwa nilai t hitung 7,232 $>\mathrm{t}$ tabel 1,694. Maka dapat menunjukkan bahwa model pembelajaran TGT mampu menumbuhkan kemampuan berpikir kritis siswa.

Berdasarkan latar belakang diatas dan mendukung penelitian sebelumnya mengenai model pembelajaran TGT. Peneliti bertujuan untuk melakukan penelitian di kelas V SDN Blotongan 03 Salatiga dengan menggunakan jenis penelitian eksperimen dengan metode Pre-eksperimental. SD Negeri Blotongan 03 sebagai kelompok perlakuan tunggal artinya hanya ada satu kelompok perlakuan dan tidak ada kelompok pembanding. Pemilihan SD sebagai tempat penelitian disebabkan memiliki latar belakang yaitu menurunnya tingkat pemahaman siswa dalam menyerap materi pelajaran dan kemampuan berpikir kritis dalam memecahkan suatu masalah juga rendah. Maka peneliti bermaksud melakukan penelitian tentang "Pengaruh Model Pembelajaran TGT (Teams Games Tournament) Ditinjau dari Kemampuan Berpikir Kritis pada Pembelajaran Tematik Siswa Kelas V SDN Blotongan 03 Tahun Ajaran 2019/2020".

\section{METODE}

Penelitian ini menggunakan jenis penelitian eksperimen, metode penelitian pre-eksperimental design dengan tipe one-group pre-test-post-test design. Menurut (Saputra, 2017:79) metode eksperimen dengan desain metode preeksperimental tipe one-group pre-test-post-test design merupakan metode eksperimen yang dilakukan hanya satu perlakuan atau satu kelompok saja tanpa ada kelompok pembanding. Tujuan penelitian ini adalah untuk mengetahui pengaruh kemampuan berpikir kritis pada pembelajaran tematik siswa kelas V SDN Blotongan 03 Tahun Ajaran 2019/2020 sebelum dan setelah menggunakan model pembelajaran TGT (Teams Games tournament). berikut ini desain metode penelitian pre-eksperimental dengan tipe one-group pre-test-post-test design menurut: 
Kritis pada Pembelajaran Tematik di Sekolah Dasar - Nur Endah Hikmah Fauziyah, Indri Anugraheni.

DOI: 10.31004/basicedu.v4i4.459

Tabel 1. One-group Pre-test-Post-test Design

\begin{tabular}{|c|c|c|}
\hline $\mathrm{O}_{1}$ & $\mathrm{X}$ & $\mathrm{O}_{2}$ \\
\hline
\end{tabular}

Keterangan :

$\mathrm{X}=$ Perlakuan (pembelajaran menggunakan model pembelajaran TGT)

$\mathrm{O}_{1}=$ Pre-test (sebelum diberi perlakuan)

$\mathrm{O}_{2}=$ Post-test (setelah diberi perlakuan)

Populasi menurut (Sukmadinata, 2012:250) merupakan kelompok besar dan wilayah yang menjadi lingkup tujuan penelitian untuk menarik kesimpulan. Populasi dalam penelitian ini adalah seluruh siswa siswa kelas V SDN Blotongan 03. Subjek penelitian ini adalah siswa kelas V SDN Blotongan 03 berjumlah 31 siswa. Sampel menurut (Sugiyono, 2010:118) adalah bagian dari jumlah dan karakteristik yang dimiliki oleh populasi tersebut. Peneliti menetapkan sejumlah 31 siswa sebagai sampel penelitian ini yang terdiri dari siswa kelas V SD Negeri Blotongan 03. Teknik pengumpulan data menurut (Sugiyono, 2010:308) merupakan langkah yang paling utama dalam penelitian, karena untuk memperoleh data dalam penelitian. Teknik pengumpulan data yang digunakan dalam penelitian ini adalah teknik tes yang berjumlah 33 soal uraian. Sedangkan teknik analisis data yaitu uji normalitas, uji homogenitas, dan uji one sample T-test menggunakan teknik one samples test dengan bantuan SPSS 20.

\section{HASIL DAN PEMBAHASAN}

Dalam penelitian ini untuk meninjau atau mengetahui kemampuan berpikir kritis siswa data diperoleh dengan melakukan penilaian pre-test dan post-test melalui pemberian soal uraian sebanyak 33 butir soal. Tes dilakukan hanya satu kelas sebagai subjek penelitian atau tidak ada kelas pembanding yaitu kelas V SDN Blotongan 03 yang berjumlah 31 siswa melalui pembelajaran tematik yaitu tema 7 Peristiwa dalam Kehidupan dan subtema 1 Peristiwa Kebangsaan Seputar Proklamasi Kemerdekaan semester II tahun pelajaran 2019/2020. Penelitian ini dilaksanakan dalam tiga tahap yaitu 1) memberikan tes awal (pre-test) sebelum memulai kegiatan pembelajaran, 2) melaksanakan pembelajaran dengan menggunakan model pembelajaran TGT, 3) memberikan tes akhir (post-test) setelah kegiatan pembelajaran. Adapun hasil perhitungan rata-rata nilai pre-test dan post-test dapat dilihat pada tabel 2 di bawah ini:

Tabel 2. Rata-rata Nilai Pre-test dan Post-test

\begin{tabular}{cc}
\hline Tes Uraian & Rata-rata \\
\hline Pre-test & 63,27 \\
Post-test & 74,12 \\
\hline
\end{tabular}

Berdasarkan hasil rata-rata nilai pre-test dan post-test terdapat peningkatan pencapaian rata-rata nilai kemampuan berpikir kritis dengan menggunakan model pembelajaran TGT. Hal ini dapat dilihat dari rata-rata nilai pre-test siswa sebelum menggunakan model pembelajaran TGT sebesar 63,27. Kemudian rata-rata nilai post-test siswa setelah menggunakan model pembelajaran TGT menjadi 74,12.

Selanjutnya peneliti melakukan uji normalitas dan uji homogenitas dari data hasil pre- 
Kritis pada Pembelajaran Tematik di Sekolah Dasar - Nur Endah Hikmah Fauziyah, Indri Anugraheni.

DOI: 10.31004/basicedu.v4i4.459

test dan post-test dengan bantuan SPSS 20. Uji normalitas menurut (Putri et al., 2018:11) digunakan untuk mengetahui apakah data berdistribusi normal atau tidak. Normalitas data dapat dilihat dari nilai signifikansinya. Kriteria uji normalitas adalah nilai signifikansi atau nilai probabilitas < 0,05 maka data berdistribusi tidak normal. Sedangkan jika nilai signifikansi atau nilai probabilitas > 0,05 maka data berdistribusi normal. Uji normalitas dapat dilihat pada tabel 3.

Berdasarkan hasil uji normalitas pada data pre-test menunjukkan nilai signifikansi 0,200 dan data post-test menunjukkan nilai signifikansi 0,185 pada Kolmogorov-Sminov. Sedangkan pada Shapiro-Wilk data pre-test menunjukkan nilai signifikansi 0,678 dan data post-test menunjukkan nilai signifikansi 0,809 . Sehingga data yang diperoleh lebih besar dari nilai signifikansi $>0,05$. Maka dapat disimpulkan bahwa data penelitian berdistribusi normal dan memenuhi syarat untuk dilakukan analisis paramaterik dari data penelitian.

Setelah dilakukan uji normalitas, langkah selanjutnya melakukan uji homogenitas dengan bantuan SPSS 20 menggunakan uji Levene. Uji homogenitas menurut (Putri et al., 2018:11) digunakan untuk mengetahui dua atau lebih kelompok data sampel dapat dinyatakan homogen atau tidak. Uji homogenitas juga digunakan sebagai persyaratan untuk dianalisis lebih lanjut. Kriteria uji homogenitas adalah jika nilai signifikansi atau nilai probabilitas $<0,05$ maka varian dari dua kelompok data berdistribusi tidak homogen. Sedangkan jika nilai signifikansi atau nilai probabilitas > 0,05 maka varian dari dua kelompok data berdistribusi homogen. Uji homogenitas dapat dilihat pada tabel 4 .

Tabel 3. Uji Normalitas

\begin{tabular}{lllllllll}
\hline & \multicolumn{1}{l}{ Kelas } & \multicolumn{4}{l}{ Kolmogorov-Smirnov } & \multicolumn{4}{l}{ Shapiro-Wilk } \\
& & Statistic & Df & Sig. & Statistic & df & Sig. \\
Kemampuan & Pre-test & .119 & 30 & $.200^{*}$ & .975 & 30 & .678 \\
Berpikir Kritis & Post-test & .133 & 30 & .185 & .979 & 30 & .809 \\
\hline
\end{tabular}

Tabel 4. Uji Homogenitas

\begin{tabular}{llllll}
\hline & \multicolumn{1}{c}{ Levene Statistic } & df1 & df2 & Sig. \\
\hline $\begin{array}{l}\text { Kemampuan } \\
\text { Berpikir Kritis }\end{array}$ & $\begin{array}{l}\text { Based on Mean } \\
\text { Based on Median }\end{array}$ & .023 & 1 & 58 & .880 \\
& $\begin{array}{l}\text { Based on Median and } \\
\text { with adjusted df }\end{array}$ & .001 & 1 & 58 & .973 \\
\hline $\begin{array}{l}\text { Based on trimmed } \\
\text { mean }\end{array}$ & .028 & 1 & 57.940 & .973 \\
\hline
\end{tabular}


Tabel 5. Uji One Sample Test

\begin{tabular}{|c|c|c|c|c|c|c|}
\hline \multirow[b]{4}{*}{$\begin{array}{l}\text { Kemampuan Berpikir } \\
\text { Kritis }\end{array}$} & \multicolumn{6}{|c|}{ Test Value $=100$} \\
\hline & \multirow[t]{2}{*}{$\mathrm{t}$} & \multirow[t]{2}{*}{ Df } & \multirow[t]{2}{*}{$\begin{array}{l}\text { Sig. (2- } \\
\text { tailed) }\end{array}$} & \multirow[t]{2}{*}{ Mean Difference } & \multicolumn{2}{|c|}{$\begin{array}{l}\text { 95\% Confidence Interval of } \\
\text { the Difference }\end{array}$} \\
\hline & & & & & Lower & Upper \\
\hline & 60.208 & 61 & .000 & 68.691 & 66.41 & 70.97 \\
\hline
\end{tabular}

Berdasarkan hasil uji homogenitas terbukti lebih besar dari nilai signifikansi $>0,05$ yaitu menunjukkan nilai signifikansi sebesar 0,880 . Maka data penelitian dapat dinyatakan homogen.

Setelah melakukan uji normalitas dan uji homogenitas dapat disimpulkan bahwa data penelitian berdistribusi normal dan homogen. Selanjutnya akan dilakukan uji hipotesis kemampuan berpikir kritis siswa sebelum dan setelah menggunakan model pembelajaran TGT dengan menggunakan uji one sample T-test melalui teknik one samples test dengan bantuan SPSS 20. Pengambilan keputusan dalam uji hipotesis yaitu Sig. (2-tailed) $<0,05$ maka $\mathrm{H}_{\mathrm{o}}$ ditolak dan $\mathrm{H}_{\mathrm{a}}$ diterima, sebaliknya apabila Sig. (2tailed) > 0,05 maka $\mathrm{H}_{\mathrm{o}}$ diterima dan $\mathrm{H}_{\mathrm{a}}$ ditolak. Hipotesis yang diuji dalam penelitian ini, yaitu:

1. $\mathrm{H}_{\mathrm{o}}$ : tidak terdapat pengaruh pengaruh kemampuan berpikir kritis pada pembelajaran tematik siswa kelas V SDN Blotongan 03 Tahun Ajaran 2019/2020 dengan menggunakan model pembelajaran TGT (Teams Games Tournament).

2. $\mathrm{H}_{\mathrm{a}}$ : terdapat pengaruh kemampuan berpikir kritis pada pembelajaran tematik siswa kelas V SDN Blotongan 03 Tahun Ajaran 2019/2020 dengan menggunakan model pembelajaran TGT (Teams Games Tournament).

Berdasarkan hasil uji one sample T-test menunjukkan bahwa terdapat pengaruh menggunakan model pembelajaran TGT yang diberikan kelas pre-eksperimen. Hal ini dapat diketahui dari hasil $\mathrm{t}$ hitung 60,208 > t tabel 1,698 dan nilai signifikansi pada kolom Sig. (2-tailed) $<0,05(0,000<0,05)$. Hal ini menunjukkan bahwa $\mathrm{H}_{\mathrm{a}}$ diterima dan $\mathrm{H}_{\mathrm{o}}$ ditolak. Oleh karena itu $\mathrm{H}_{\mathrm{a}}$ menunjukkan bahwa terdapat pengaruh yang signifikan kemampuan berpikir kritis siswa pada pembelajaran tematik dengan memberikan pre-test dan post-test menggunakan model pembelajaran TGT.

Penelitian ini didukung oleh (Aisyah, 2019:8) yang telah melakukan penelitian tentang Penerapan Model Teams Games Tournament (TGT) dengan Permainan Teka-Teki Silang (TTS) terhadap Kemampuan Berpikir Kritis Peserta Didik. Hasil penelitian menunjukkan bahwa terdapat peningkatan kemampuan berpikir kritis peserta didik melalui model pembelajaran TGT. Hal ini dapat dilihat dari nilai $\mathrm{t}$ hitung 31,243>t tabel 1,6957 dan peningkatan terhadap nilai pretest dan post-test yaitu sebesar 30,15. 
Kritis pada Pembelajaran Tematik di Sekolah Dasar - Nur Endah Hikmah Fauziyah, Indri Anugraheni.

DOI: 10.31004/basicedu.v4i4.459

Penelitian lain juga dilakukan oleh (Putri et al., 2018:12-13) yang telah melakukan penelitian tentang Peningkatan Kemampuan Berpikir Kritis Siswa Melalui Metode Pembelajaran Team Games Tournaments dan Team Assisted Individualization. Hasil penelitian menunjukkan bahwa model pembelajaran Team Games Tournaments (TGT) lebih baik diterapkan dalam meningkatkan kemampuan berpikir kritis siswa dibandingkan model pembelajaran Team Assisted Individualization (TAI). Hal ini dapat dilihat dari dari N-Gain pada kelas eksperimen I yaitu model pembelajaran TGT memperoleh hasil sebesar 0,776 dan sedangkan kelas eksperimen II yaitu model pembelajaran TAI memperoleh hasil sebesar 0,664. Dapat dilihat juga dari nilai t hitung 5,361 > t tabel 1,99444.

Berdasarkan uraian diatas dapat diketahui bahwa 1) kemampuan berpikir kritis pada pembelajaran tematik siswa sebelum menggunakan model pembelajaran TGT (Teams Games Tournament) nilai rata-rata sebesar 63,27. 2) kemampuan berpikir kritis pada pembelajaran tematik siswa setelah menggunakan model pembelajaran TGT (Teams Games Tournament) nilai rata-rata sebesar 74,12. 3) hasil analisis data one sample T-test menggunakan teknik one samples test diperoleh hasil $\mathrm{t}$ hitung 60,208 > $\mathrm{t}$ tabel 1,698 dan nilai signifikansi pada kolom Sig. (2- tailed $)<0,05(0,000<0,05)$. Hal ini menunjukkan bahwa terdapat pengaruh kemampuan berpikir kritis pada pembelajaran tematik siswa kelas V SDN Blotongan 03 Tahun Ajaran 2019/2020 dengan menggunakan model pembelajaran TGT (Teams Games Tournament).

\section{SIMPULAN}

Berdasarkan hasil rata-rata nilai pre-test dan post-test terdapat peningkatan pencapaian rata-rata nilai kemampuan berpikir kritis dengan menggunakan model pembelajaran TGT. Hal ini dapat dilihat dari rata-rata nilai pre-test siswa sebelum menggunakan model pembelajaran TGT sebesar 63,27. Kemudian rata-rata nilai post-test siswa setelah menggunakan model pembelajaran TGT menjadi 74,12.

Hal ini dibuktikan melalui hasil analisis data one sample T-test menggunakan teknik one samples test diperoleh hasil $\mathrm{t}$ hitung 60,208 > t tabel 1,698 dan nilai signifikansi pada kolom Sig. (2- tailed) $<0,05(0,000<0,05)$. Maka $\mathrm{H}_{\mathrm{a}}$ diterima dan $\mathrm{H}_{\mathrm{o}}$ ditolak. Oleh karena itu dapat ditarik kesimpulan $\mathrm{H}_{\mathrm{a}}$ menunjukkan bahwa terdapat pengaruh yang signifikan kemampuan berpikir kritis siswa pada pembelajaran tematik dengan memberikan pre-test dan post-test menggunakan model pembelajaran TGT.

Berdasarkan hasil penelitian yang telah dilakukan tentunya terdapat kekurangan dan kelebihan dalam menerapkan model pembelajaran TGT. Adapun kekurangan penerapan model pembelajaran TGT yaitu membutuhkan waktu yang cukup lama untuk melakukan games tournament dan ruang kelas menjadi sangat ramai sehingga dapat mengganggu ruang kelas yang lain. Sedangkan kelebihan menerapkan model pembelajaran TGT yaitu siswa yang biasanya pasif menjadi lebih aktif dan dapat merangsang berpikir kritis siswa dalam memunculkan ide untuk memecahkan suatu masalah. 

Kritis pada Pembelajaran Tematik di Sekolah Dasar - Nur Endah Hikmah Fauziyah, Indri Anugraheni.

DOI: 10.31004/basicedu.v4i4.459

Peneliti menyarankan bagi para guru diharapkan dapat menggunakan model pembelajaran TGT agar siswa terlibat aktif dan mampu menumbuhkan kemampuan berpikir kritis dengan cara mengkaitkan materi pembelajaran dengan kehidupan sehari-hari dan mengkaitkan masalah yang sedang terjadi di kehidupan nyata. Kemudian bagi Kepala Sekolah diharapkan dapat menjadi pertimbangan dalam pelaksanaan supervisi sekolah. Sedangkan bagi peneliti selanjutkan, diharapkan menjadi referensi dan pertimbangan untuk memperoleh hasil yang lebih maksimal dalam melakukan penelitian dengan menggunakan model pembelajaran TGT terhadap berpikir kritis siswa.

\section{DAFTAR PUSTAKA}

Aisyah, N. (2019). Penerapan Model Teams Games Tournament (TGT) dengan Permainan Teka-Teki Silang (TTS) terhadap Keterampilan Berpikir Kritis Peserta Didik. Cakrawala: Jurnal Pendidikan, 13(2), 1-11.

Anugraheni, I. (2017). PENGGUNAAN PORTOFOLIO DALAM PERKULIAHAN PENILAIAN PEMBELAJARAN Indri. Jurnal Pendidikan Dasar PerKhasa.

Anugraheni, I. (2019). Analisis Kemampuan Berpikir Kritis Mahasiswa Dalam Menyelesaikan Permasalahan Bilangan Bulat Berbasis Media Realistik. Scholaria: Jurnal Pendidikan Dan Kebudayaan. https://doi.org/10.24246/j.js.2019.v9.i3.p276283

Emzir. (2012). METODOLOGI PENELITIAN PENDIDIKAN: KUANTITATIF DAN KUALITATIF. Jakarta: PT. RAJAGRAFINDO PERSADA.

Hermawan, A., \& Rahayu, T. S. (2020). Penerapan Pendekatan Saintifik dan Model Team Games Tournament Terhadap Motivasi
Belajar Siswa Sekolah Dasar. Jurnal Basicedu.

https://doi.org/10.31004/basicedu.v4i2.386

Huda, M. (2013). MODEL-MODEL PENGAJARAN DAN PEMBELAJARAN: ISU-ISU METODIS DAN PARADIGMATIS. Yogyakarta: Pustaka Pelajar.

Lailatifah, S. (2018). EFEKTIVITAS MODEL PEMBELAJARAN TGT DAN STAD DITINJAU DARI KEMAMPUAN BERPIKIR KRITIS. Jurnal Pendidikan Matematika - S1, 7(5).

Maulana. (2017). Konsep Dasar Matematika dan Pengembangan Kemampuan Berpikir KritisKreatif. Sumedang: UPI Sumedang Press.

Sukmadinata, N. S. (2012). Metode Penelitian Pendidikan. Bandung: PT. REMAJA ROSDAKARYA.

Ni Md. Rusnadi, D. P. P. N. W. A. (2013). PENERAPAN MODEL PEMBELAJARAN KOOPERATIF TIPE TEAM GAMES TOURNAMENT UNTUK MENINGKATKAN KEMAMPUAN BERPIKIR KRITIS DAN HASIL BELAJAR IPA. In MIMBAR PGSD.

Novika Hapsari Susilo, Arfilia Wijayanti, F. P. A. (2019). Penerapan Permainan What's In Here Berbasis Model TGT untuk Menumbuhkan Kemampuan Berpikir Kritis Siswa. EJournal Undiksha.

Pardede, U. T. (2019). PENIGKATAN KEMAMPUAN BERPIKIR KRITIS SISWA MELALUI MODEL PEMBELAJARAN KOOPERATVE TIPE TGT DI SMAN 1 BATANG TORU. Mathematic Education Journal, 2(1), 67-74.

Putri, D. A., Suwatno, S., \& Sobandi, A. (2018). PENINGKATAN KEMAMPUAN BERPIKIR KRITIS SISWA MELALUI METODE PEMBELAJARAN TEAM GAMES TOURNAMENTS DAN TEAM ASSISTED INDIVIDUALIZATION. Jurnal MANAJERIAL.

https://doi.org/10.17509/manajerial.v17i1.97 

Kritis pada Pembelajaran Tematik di Sekolah Dasar - Nur Endah Hikmah Fauziyah, Indri Anugraheni.

DOI: $10.31004 /$ basicedu.v4i4.459

39

Saputra, A. (2017). Penggunaan Media Pop-up sebagai Peningkatan Kemampuan Menulis Karangan Narasi Ekspositorik. PEDADIDAKTA: JURNAL ILMIAH PENDIDIKAN GURU SEKOLAH DASAR, 4(2), 76-84.

Slavin, R. E. (2010). Cooperative Learning (Riset dan Praktik). Bandung: Nusa Media.

Sugiyono. (2010). Metode Penelitian Pendidikan (Pendekatan Kuantitatif, Kualitatif, dan $R \& D)$. Bandung: Alfabeta Bandung.

Surata, I. G., Agung, A. A., \& Sudarma, G. K. (2013). Pengaruh Model Kooperatif STAD Berorientasi Open-Ended Problem terhadap Keterampilan Berpikir Kritis dalam Pembelajaran IPA Siswa Kelas V Sekolah Dasar. Mimbar PGSD Undiksha. https://doi.org/10.23887/JJPGSD.V1I1.688

Winoto, Y. C., \& Prasetyo, T. (2020). EFEKTIVITAS MODEL PROBLEM BASED LEARNING DAN DISCOVERY LEARNING TERHADAP KEMAMPUAN BERPIKIR KRITIS SISWA SEKOLAH DASAR. Jurnal Basicedu. https://doi.org/10.31004/basicedu.v4i2.348 